\title{
Association of Heterorhabditis amazonensis and Beauveria bassiana aiming the control of Hypothenemus hampei
}

\author{
Igor Bitencourt Lima Moreira1 (iD), Vanessa Andaló1 (iD), Gleice Aparecida de Assis¹ (iD, Lucas Silva de Faria1 (iD), \\ Fabio Janoni Carvalho ${ }^{\text {(D) }}$, Renan Zampiroli ${ }^{1}$ (iD)
}

${ }^{1}$ Universidade Federal de Uberlândia, Monte Carmelo, MG, Brasil
${ }^{2}$ Instituto Federal do Triângulo Mineiro, Uberaba, MG, Brasil
Contact author: igorbitencourt@ufu.br, vanessaandalo@ufu.br, gleiceufu@gmail.com, lucassilvafaria@hotmail.com, fjcarvalho1@gmail.com, renanzampiroli@ufu.br
Received in June 24, 2020 and approved in November 23, 2020

\begin{abstract}
Among the main problems for coffee production, it is possible to mention the occurrence of coffee borer, Hypothenemus hampei. In order to seek alternatives to control the pest, the proposed objective was to evaluate the interaction between Beauveria bassiana UFU01 and Heterorhabditis amazonensis MC01 on the control of coffee borer. Therefore, four experiments were set. In the first, B. bassiana UFU01, H. amazonensis MC01 and both entomopathogens associated were applied in bored fruits displaced in vermiculite. In the second experiment, the methodology was similar to the previous one; however, the fruits were immersed in the suspensions. In the third experiment was evaluated the transport of $B$. bassiana UFU01 conidia by $H$. amazonensis, checking the mortality of Tenebrio molitor. In the fourth experiment, the fungus and the nematode were added to Petri dishes containing agar-water simultaneously to observe if the nematodes could carry $B$. bassiana UFU01 conidia. The obtained data were subjected to analysis of variance and the Tukey test $(p<0.05)$, for comparison between means and regression analysis. It was found that, when entomopathogens were applied to vermiculite, treatments using $B$. bassiana UFU01 and $H$. amazonensis alone caused the highest mortality of $H$. hampei adults. For larvae, there was no difference among treatments. The same was observed when the fruits were dipped in the suspensions, with no difference among treatments. As for $T$. molitor mortality, it was observed that there was no difference among treatments. However, when applied in combination, there was a higher mortality caused by $B$. bassiana compared to $\mathrm{H}$. amazonensis. In the last experiment, juveniles and conidia were found on the opposite side of the dish, and it can be inferred that the presence of conidia was due to transport by infective juveniles.
\end{abstract}

Key words: Biological control; Coffea; Entomopathogenic fungus; Entomopathogenic nematode.

\section{INTRODUCTION}

Brazil has gained great prominence in the coffee sector, with 2.16 million hectares of total area cultivated with coffee and the estimate for the year 2020, considering the positive period, is to reach between 57.2 million and 62.02 million processed bags (Companhia Nacional de Abastecimento CONAB, 2020).

Among the obstacles to coffee production, the occurrence of coffee borer, Hypothenemus hampei (Ferrari) (Coleoptera: Scolytidae) can be highlighted. This insect is associated with annual losses of U\$\$ 500 million, affecting the income of more than 20 million rural producers in about 80 countries (Infante; Pérez; Vega, 2012). The losses are mainly associated with direct injuries caused to the fruits, which lead to weight loss and early fall (Oliveira et al., 2013). Adult $H$. hampei females make galleries in the endosperm of the coffee seed, reducing the production and quality of the final product, due to early fall, delay in development and fruit rotting (Parra; Reis, 2013). Thus, coffee borer causes the product to depreciate in terms of physical classification, as it compromises the sensory quality of the beverage (Souza et al., 2013).

Borer control through the chemical method is considered difficult due to the cryptic habit of the insect, remaining inside the fruit. In addition, due to poor harvest, many fruits are hanging on the plant or fallen on the ground, which serves as a shelter for the borer, intensifying infestation in the next harvest. The appropriate measures to avoid that post-harvest fruits remain in the field, in most cases, are not taken, thus causing an increase in pest incidence and making the reduction in population levels even more difficult (Carvalho; Souza, 2020).

The insecticide endosulfan used to be widely applied in the control of coffee borer. However, in 2013, its use was banned by the National Sanitary Surveillance Agency (ANVISA). Thus, after its prohibition, many efforts have been made in order to obtain a new product for this purpose, with a series of products being registered for the control of coffee borer (Brasil, 2020; Plata-Rueda et al., 2019; Souza et al., 2013), but it is understood that, for a better pest control, it is necessary to take joint control measures, adopting the concepts of integrated management.

Among other methods that can be applied in the control of coffee borer, the use of biological control can be considered potential, as long as crop management practices are taken into account. Entomopathogenic nematodes (Nematoda: Rhabditida) from the families Heterorhabditidae and Steinernematidae are potential pest control agents (Dolinski et al., 2017). According to Divya and Sankar (2009), the application of nematodes to bored fruits that fall on the soil 
helps control the pest insect. The authors also indicate that the dispersion of $H$. hampei adults helps in the spread of the nematode in the field to other areas, allowing the colonization of other hosts. Allard and Moore (1989) considerate that Heterorhabditis sp. can cause coffee borer mortality of both larvae and adults, and can produce new generations of nematodes that will remain in the field in the search of new hosts.

Entomopathogenic fungi can also help in the control of coffee borer. The fungus Beauveria bassiana (Bals.) (Hypocreales: Cordycipitaceae) acts on several insect orders and is capable of causing epizootics in H. hampei. However, there are differences related to the fungus control potential in the field due to management practices adopted in each area, which can favor or hinder the occurrence of the fungus (Damon, 2000; Monzón; Guharay; Klingen, 2008).

Considering the possible application of entomopathogens directed to the soil in order to reach fallen bored fruits, the objective of this study was to verify the potential of $B$. bassiana UFU01 and the entomopathogenic nematode Heterorhabditis amazonensis MC01 applied alone and associated in the control of H. hampei under laboratory conditions.

\section{MATERIAL AND METHODS}

\subsection{Association of Beauveria bassiana and Heterorhabditis amazonensis}

The fungus and the entomopathogenic nematode used in the experiments were obtained from the bank of entomopathogens of Federal University of Uberlândia, MG, Brazil. The nematode was isolated from the soil using insect bait and the fungus was isolated from an H. hampei adult, both in the region of Monte Carmelo, MG, Brazil.

For the evaluation of $H$. hampei mortality caused by $B$. bassiana UFU01 and $H$. amazonensis MC01, two experiments were conducted under laboratory conditions. For each experiment, about 450 bored fruits were collected in a coffee field at approximately six years of age, located at the coordinates $\left(18^{\circ} 44^{\prime} 46.2^{\prime \prime} \mathrm{S}, 4^{\circ} 31^{\prime} 07.6^{\prime \prime} \mathrm{W}\right)$, with a total of 5 ha of 'Rubi MG-1192' Coffea arabica L., spacing of $3.50 \mathrm{~m}$ between rows $\times 0.80 \mathrm{~m}$ between plants. The harvested fruits were taken to the laboratory where the material was sorted, selecting the fruits with injuries related to the presence of coffee borer.

The first experiment consisted of three treatments and the control, with 10 replications each. The treatments were: commercial product based on B. bassiana UFU01, applying $1 \mathrm{~mL}$ of suspension at a concentration of $1 \times 10^{9}$ conidia $\mathrm{mL}^{-1} ; H$. amazonensis $\mathrm{MC} 01$ at a concentration of 1,200 infective juveniles (IJs) $\mathrm{mL}^{-1}$ (150 IJ per fruit); and the association of B. bassiana UFU01 and H. amazonensis $\mathrm{MC} 01,0.5 \mathrm{~mL}$ of each suspension at the same previous concentrations. In the control, only $20 \mathrm{~mL}$ of water were applied. Both entomopathogens and water were added to vermiculite using a micropipette (Figure 1).

To set this experiment, which started on the same day as fruit collection, $0.09 \mathrm{~m}$ Petri dishes were used, containing $0.0045 \mathrm{~kg}$ of vermiculite in each dish, to which $19 \mathrm{~mL}$ of water were added in order to moisten the substrate. Eight bored fruits were placed per dish, so that they were covered by vermiculite, totaling 320 fruits.

The dishes were closed and sealed with Parafilm ${ }^{\circledR}$ and kept in a climatic chamber at $24 \pm 1^{\circ} \mathrm{C}$, with a 12 -hour photoperiod. Evaluations of larval and adult mortality of coffee borer started four days after the application of treatments for five days (totaling nine days of contact with the suspensions), with two replications per day being evaluated. The verification was carried out with the help of a utility knife, cutting the fruit in half and analyzing it. After the evaluation, the dead insects were placed in a humid chamber to confirm mortality by entomopathogens.

For the second experiment, the bored fruits were dipped into suspensions with the fungus and the nematode, alone or together. The experiment consisted of three treatments and a control, with five replications each. Ten fruits were used for replication. The suspensions were prepared at the same concentrations as the previous assay to obtain a final volume of $100 \mathrm{~mL}$ each. In the association of $B$. bassiana UFU01 and $H$. amazonensis $\mathrm{MC} 01,50 \mathrm{~mL}$ of suspension with the nematode and $50 \mathrm{~mL}$ of the suspension containing the fungus were used, keeping the concentration of the entomopathogens. In the control, only water was used.

To submerge the fruits, they were placed in measuring cylinders $(200 \mathrm{~mL})$ and the suspensions were then added, keeping the fruits submerged for 5 seconds. After contact with the products, they were placed in Petri dishes $(0.09 \mathrm{~m}$ in diameter) lined with a sheet of filter paper. The dishes were closed with Parafilm ${ }^{\circledR}$ and kept in climatic chamber at $24^{\circ} \mathrm{C} \pm$ $1^{\circ} \mathrm{C}$ with a 12 -hour photoperiod.

Evaluations of larval and adult mortality of coffee borer started 11 days after the application of entomopathogens, and all replications were analyzed on the same day. The dead insects were kept in a humid chamber to confirm mortality. A General Linear Model was adjusted for the data of the first experiment with a binomial distribution and a logit link function. Analysis of deviance was performed to detect significant difference in the factors using Chi-Squared test. For the second experiment, with normal distribution and homocesdasticity, data was submitted to Analysis of Variance (ANOVA). If the the means were considered different, Tukey's test $(p<0.05)$ was applied for the treatments, and regression analysis was performed for the time of evaluation. 


\subsection{Phoresis of Beauveria bassiana by} Heterorhabditis amazonensis

To verify the possible transport of $B$. bassiana UFU01 conidia by $H$. amazonensis MC01, two experiments were carried out. The first experiment was conducted using Tenebrio molitor L. (Coleoptera: Tenebrionidae) larvae, created according to the methodology of Potrich et al. (2007), arranged in Petri dishes $(0.09 \mathrm{~m}$ in diameter) containing $0.0045 \mathrm{~kg}$ of vermiculite. A steel screen $(0.01 \mathrm{~m}$ high, $0.09 \mathrm{~m}$ wide) was placed in the center of the dish in order to divide the dish into two sides and keep the larvae on only one side of the dish.

Five T. molitor larvae were placed on one side of each dish. In the control and in the treatment with B. bassiana, water and the fungus, respectively, were applied on the entire dish, while in the treatments with the nematode and the association of $B$. bassiana with the nematode, entomopathogens were added on only one side of the dish, opposite to the presence of T. molitor. Three treatments were used: B. bassiana, $H$. amazonensis and the association of the two entomopathogens. Each treatment consisted of 10 replications.

Vermiculite was first moistened with $14 \mathrm{~mL}$ of water and the suspensions were then applied. For B. bassiana, $1 \mathrm{~mL}$ of suspension was used at a concentration of $1 \times 10^{9}$ conidia. Heterorhabditis amazonensis MC01 was added to vermiculite at a concentration of $1,200 \mathrm{IJ} \mathrm{mL}^{-1}$. For the association between $B$. bassiana and $H$. amazonensis, $0.5 \mathrm{~mL}$ of each suspension was added at the same previous concentrations. In the control, $15 \mathrm{~mL}$ of water were added. No type of diet was provided for the insects inside the dishes.

The dishes were properly closed and sealed using Parafilm $^{\circledR}$ and kept in climatic chamber at $24 \pm 1{ }^{\circ} \mathrm{C}$ with a 12-hour photoperiod. The mortality of T. molitor larvae was assessed after 12 days, evaluating insect mortality; thus, it was verified if there were conidia on the side of the dish where it was not applied. In the dead larvae, the characteristic symptoms of death by the entomopathogen were verified and, when necessary, they were kept in a humid chamber or dissected.

The second experiment was set in order to observe the possible transport of $B$. bassiana conidia by $H$. amazonensis IJs when inoculated together in Petri dishes containing agar-water. Therefore, 20 Petri dishes $(0.09 \mathrm{~m}$ in diameter) containing $20 \mathrm{~mL}$ of water-agar per dish at a concentration of $1 \%$ were used.

Three treatments and a control were used, with five replications, arranged in a completely randomized design, as follows: B. bassiana UFU01, at a concentration of $1 \times 10^{9}$ conidia $\mathrm{mL}^{-1} ; H$. amazonensis $\mathrm{MC01}$ at a concentration of $1,200 \mathrm{IJ} \mathrm{mL}^{-1}$; and the association of $B$. bassiana UFU01 and $H$. amazonensis $\mathrm{MC01}$ at the same previous concentrations and in equal volumes. In the control, only water was used.
For each treatment, $0.25 \mathrm{~mL}$ of the suspension of one side of the dish were added, subsequently closed with Parafilm ${ }^{\circledR}$ and kept in climatic chamber at $24 \pm 1^{\circ} \mathrm{C}$ for 24 hours darkness; the evaluation was performed after seven days. The evaluations were performed in a stereomicroscope, verifying the presence of IJs and conidia on both sides of the dish, in order to observe if there was conidia transport by the nematode. The data obtained were submitted to analysis of variance and the Tukey test $(p<0.05)$ to compare the treatment means.

The statistical analysis was performed in $\mathrm{R}$ software version 3.5.0 and the graphical artwork in SigmaPlot version 11.

\section{RESULTS}

\subsection{Association of Beauveria bassiana and Heterorhabditis amazonensis}

Regarding the mortality of $H$. hampei adults when entomopathogens were applied to vermiculite, it was found that there was no interaction between treatments and times of evaluation ( $p=0.628)$, using the data obtained from final coffee borer mortality. There was no difference between the treatments using B. bassiana UFU01 and $H$. amazonensis MC01 alone, but they caused higher mortality than the treatment with the pathogens applied together and the control $(\mathrm{p}=0.003)($ Table 1$)$.

Table 1: Mortality of Hypothenemus hampei adults caused by Beauveria bassiana and Heterorhabditis amazonensis MC01 after five days of evaluation. Temperature of $24 \pm 1^{\circ} \mathrm{C}$ and $12-$ hour photoperiod.

\begin{tabular}{cc}
\hline Treatment & Mortality $(\%)^{*}$ \\
\hline Beauveria bassiana & $28.16 \pm 8.73 \mathrm{a}$ \\
Heterorhabditis amazonensis MC01 & $27.97 \pm 8.74 \mathrm{a}$ \\
H. amazonensis MC01 + B. bassiana & $0.76 \pm 0.87 \mathrm{~b}$ \\
Control & $0.01 \pm 1.11 \mathrm{~b}$ \\
\hline
\end{tabular}

* Means \pm standard deviation followed by the same letter did not differ significantly by the Tukey's test at $5 \%$ significance.

Considering the mortality of adults throughout the evaluation periods, it is possible to observe that there was an increase in insect mortality, reaching more than $40 \%$ of dead adults (Figure 1).

When analyzing the mortality of coffee borer larvae, an interaction was observed between evaluation periods and treatments $(p=0.043)$. From the 3rd day of evaluation, there was a significant difference between treatments and the control; the same was observed until the 5th day of evaluation (Table 2). 


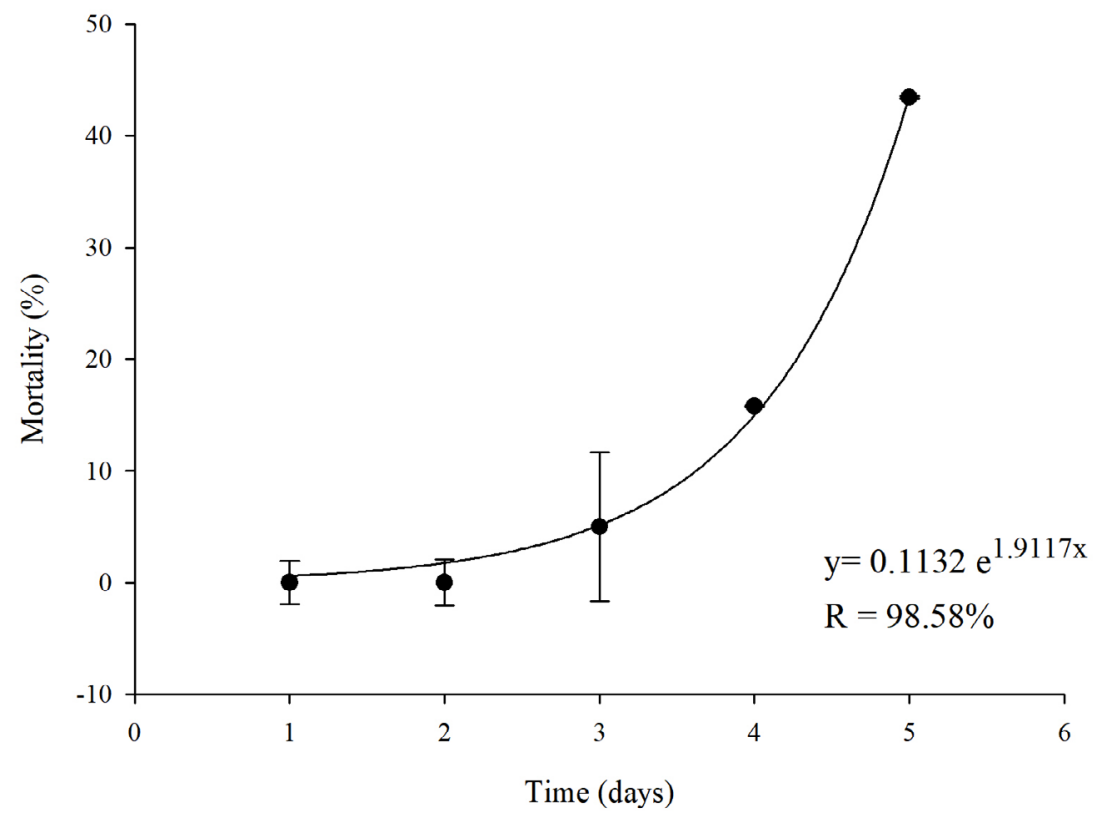

Figure 1: Total mortality of Hypothenemus hampei adults (\%) caused by the entomopathogens in five days of evaluation. Temperature of $24 \pm 1^{\circ} \mathrm{C}$ and 12-hour photoperiod.

Table 2: Mortality of Hypothenemus hampei larvae (\%) caused by Beauveria bassiana UFU01 $\left(1 \times 10^{9} \mathrm{conidia} \mathrm{mL}^{-1}\right)$ and Heterorhabditis amazonensis MC01 $\left(1,200 \mathrm{IJ} \mathrm{mL}^{-1}\right)$ kept in dishes with vermiculite for each day of evaluation. Temperature of 24 $\pm 1^{\circ} \mathrm{C}$ and 12-hour photoperiod.

\begin{tabular}{cccccc}
\hline & \multicolumn{5}{c}{ Mortality (\%) $^{*}$} \\
\cline { 2 - 6 } Treatment & \multicolumn{4}{c}{ Evaluation period (days) } \\
\cline { 2 - 6 } & $1^{\text {st }}$ & $2^{\text {nd }}$ & $3^{\text {rd }}$ & $4^{\text {th }}$ & $5^{\text {th }}$ \\
\hline B. bassiana & $38.46 \pm 13.49 \mathrm{a}$ & $76.47 \pm 10.29 \mathrm{a}$ & $68.42 \pm 10.66 \mathrm{a}$ & $81.25 \pm 9.76 \mathrm{a}$ & $75.00 \pm 12.50 \mathrm{a}$ \\
H. amazonensis & $52.94 \pm 12.11 \mathrm{a}$ & $72.22 \pm 10.56 \mathrm{a}$ & $75.00 \pm 10.83 \mathrm{a}$ & $76.47 \pm 10.29 \mathrm{a}$ & $92.30 \pm 7.39 \mathrm{a}$ \\
B. bassiana + H. amazonensis & $48.57 \pm 8.45 \mathrm{a}$ & $25.00 \pm 10.83 \mathrm{~b}$ & $69.23 \pm 12.80 \mathrm{a}$ & $66.67 \pm 9.62 \mathrm{a}$ & $93.33 \pm 6.44 \mathrm{a}$ \\
Control & $29.41 \pm 11.05 \mathrm{a}$ & $20.00 \pm 8.94 \mathrm{~b}$ & $23.07 \pm 11.69 \mathrm{~b}$ & $11.11 \pm 7.41 \mathrm{~b}$ & $18.75 \pm 9.76 \mathrm{~b}$ \\
\hline
\end{tabular}

*Means \pm standard deviation followed by the same letter did not differ significantly by the Tukey's test at $5 \%$ significance.

According to the regression analysis, different behaviors were observed in the linear and polynomial models of the tested treatments. For B. bassiana, it was found that, until the 4th day of evaluation, a mortality of $81.25 \%$ was obtained and, from this day, there was a reduction in larval death, while for the nematode and the association between the nematode and the fungus, a growth until the 5th day of evaluation was verified, obtaining, respectively, mortalities of $92.30 \%$ and $93.33 \%$ (Table 2 and Figure 2). Thus, the data obtained in this experiment demonstrate the potential of the entomopathogens in causing mortality to $H$. hampei larvae.

Considering the results obtained when bored fruits were dipped in suspensions with entomopathogens, for $H$. hampei adults, no significant difference was observed between treatments, differing only from the control (Table 3). The indexes found can be considered satisfactory, reaching 50\% of adult mortality.

Related to larval mortality, it was observed that there was no difference between the treatments tested, but they differed from the control. In addition, high insect mortality rates were obtained, reaching values of up to $98 \%$ of dead larvae (Table 4).

\subsection{Phoresis of Beauveria bassiana by Heterorhabditis amazonensis}

When analyzing the mortality of $T$. molitor after 12 days of entomopathogen release, it was observed that there was no difference between the treatments tested, but they differed from the control. In addition, high insect mortality rates were obtained, reaching values of up to $96 \%$ of dead larvae (Table 5). 

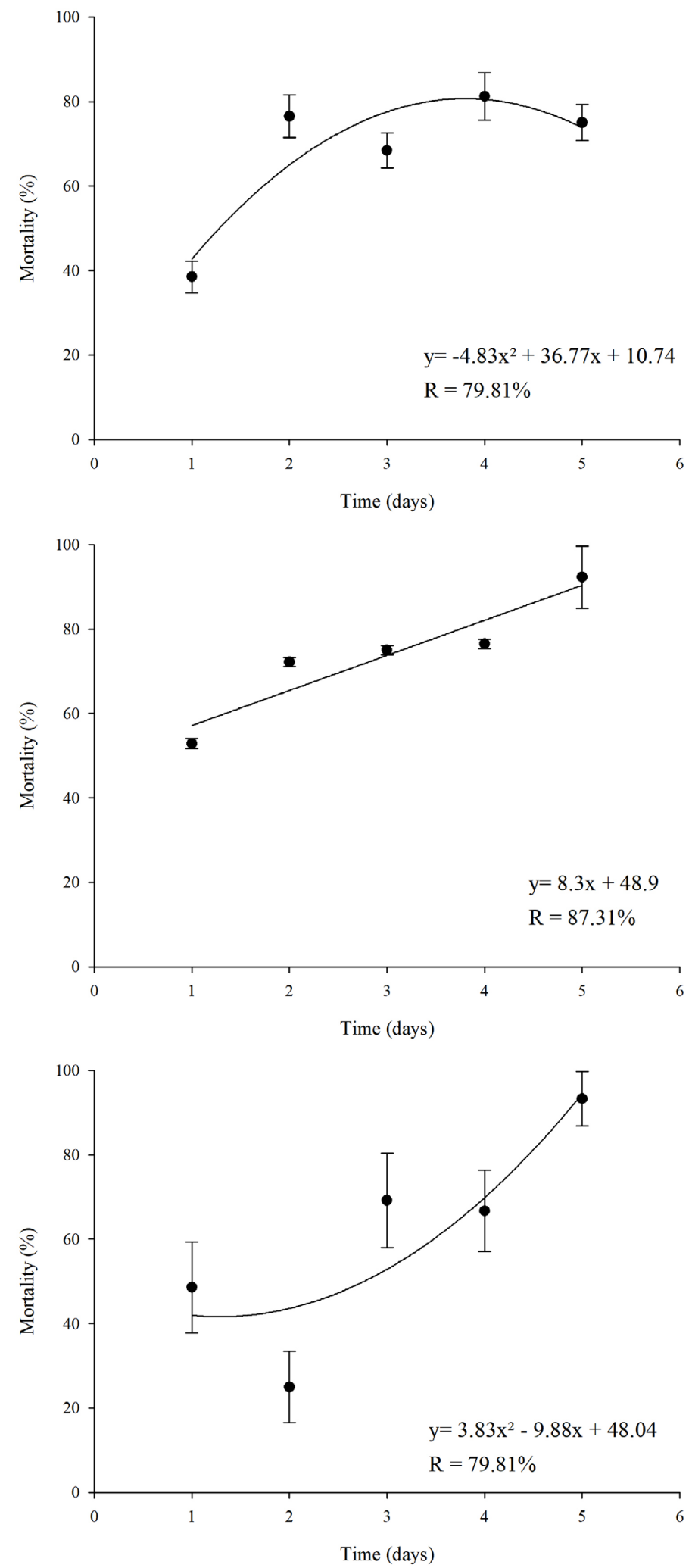

Figure 2: Mortality of Hypothenemus hampei larvae caused by Beauveria bassiana UFU01 and Heterorhabditis amazonensis MC01 and association between entomopathogens during five days of evaluation. A. Beauveria bassiana. B. Heterorhabditis amazonensis MC01. C. Beauveria bassiana + Heterorhabditis amazonensis MC01. Temperature of $24 \pm 1^{\circ} \mathrm{C}$ and 12 -hour photoperiod. 
Table 3: Mortality of Hypothenemus hampei adults (\%) when immersed in Beauveria bassiana UFU01 and Heterorhabditis amazonensis MC01 suspensions after 11 days of evaluation. Temperature of $24 \pm 1^{\circ} \mathrm{C}$ and 12-hour photoperiod.

\begin{tabular}{cc}
\hline Treatment & Mortality (\%)* \\
\hline Heterorhabditis amazonensis MC01 & $52.1 \pm 22.6 \mathrm{a}$ \\
H. amazonensis MC01 + B. bassiana & $52.0 \pm 12.6 \mathrm{a}$ \\
Beauveria bassiana & $44.6 \pm 15.0 \mathrm{a}$ \\
Control & $0.0 \pm 0.0 \mathrm{~b}$ \\
CV (\%) & 37.16 \\
\hline
\end{tabular}

*Means \pm standard deviation followed by the same letter do not differ significantly by the Tukey test at $5 \%$ significance.

Table 4: Mortality of Hypothenemus hampei larvae when immersed in Beauveria bassiana UFU01 and Heterorhabditis amazonensis MC01 suspensions after 11 days of evaluation. Temperature of $24 \pm 1^{\circ} \mathrm{C}$ and 12-hour photoperiod.

\begin{tabular}{cc}
\hline Treatment & Mortality $(\%)^{*}$ \\
\hline H. amazonensis MC01 + B. bassiana & $98.0 \pm 4.5 \mathrm{a}$ \\
Heterorhabditis amazonensis MC01 & $92.2 \pm 10.8 \mathrm{a}$ \\
Beauveria bassiana & $86.6 \pm 12.4 \mathrm{a}$ \\
Control & $0.0 \pm 0.0 \mathrm{~b}$ \\
CV $(\%)$ & 12.33 \\
\hline
\end{tabular}

*Means \pm standard deviation followed by the same letter do not differ significantly by the Tukey test at $5 \%$ significance.

Table 5: Mortality of Tenebrio molitor larvae (\%) caused by Beauveria bassiana UFU01 and Heterorhabditis amazonensis MC01 after 12 days of evaluation. Temperature of $24 \pm 1^{\circ} \mathrm{C}$ and 12-hour photoperiod.

\begin{tabular}{cc}
\hline Treatment & Mortality (\%)* \\
\hline Beauveria bassiana & $96.0 \pm 8.4 \mathrm{a}$ \\
H. amazonensis MC01 + B. bassiana & $96.0 \pm 8.4 \mathrm{a}$ \\
Heterorhabditis amazonensis MC01 & $88.0 \pm 10.3 \mathrm{a}$ \\
Control & $0.0 \pm 0.0 \mathrm{~b}$ \\
CV (\%) & 11.27 \\
\hline
\end{tabular}

*Means \pm standard deviation followed by the same letter do not differ significantly by the Tukey test at $5 \%$ significance.

When comparing the mortality caused by $B$. bassiana and $H$. amazonensis $\mathrm{MC} 01$ applied together, it can be observed that there was a significant difference between the amount of insects died by entomopathogens, verifying that $B$. bassiana yielded an increase of $44 \%$ in mortality in relation to the nematode (Table 6). As B. bassiana was applied only on the side opposite to the presence of $T$. molitor larvae, it can be inferred that the nematode helped in the dispersion in fungal conidia, with a phoretic association.
Table 6: Mortality of Tenebrio molitor larvae (\%) caused by each entomopathogen, Beauveria bassiana UFU01 and Heterorhabditis amazonensis MC01, when applied together after 12 days of evaluation. Temperature of $24 \pm 1{ }^{\circ} \mathrm{C}$ and 12 hour photoperiod.

\begin{tabular}{cc}
\hline Treatment & Mortality (\%)* \\
\hline Beauveria bassiana & $70.0 \pm 14.1 \mathrm{a}$ \\
Heterorhabditis amazonensis MC01 & $26.0 \pm 16.4 \mathrm{~b}$ \\
CV (\%) & 31.97 \\
\hline
\end{tabular}

*Means \pm standard deviation followed by the same letter do not differ significantly by the Tukey test at $5 \%$ significance.

Regarding the evaluation of $B$. bassiana conidia transport applied together with $H$. amazonensis MC01 infective juveniles in agar plates, it was found that in the control and in the treatment with the fungus alone, no entomopathogenic propagules were found on the opposite side of the dish. In the treatment with the nematode, infective juveniles were found on the opposite side of the dish. In the treatment with the association of fungus and nematode, juveniles and conidia were found on the opposite side of the dish, and it can be inferred that the presence of conidia was due to the transport made by infectve juveniles (Table 7).

Table 7: Number of individual and associated Beauveria bassiana UFU01 conidia and/or Heterorhabditis amazonensis MC01 infective juveniles found on the opposite side of the Petri dish application. Temperature of $24 \pm 1^{\circ} \mathrm{C}$ and 24-hour darkness.

\begin{tabular}{cc}
\hline Treatment & $\begin{array}{c}\text { Total number of } \\
\text { entomopathogenic } \\
\text { propagules* }\end{array}$ \\
\hline H. amazonensis MC01 + B. bassiana & $5.4 \pm 1.5 \mathrm{a}$ \\
Heterorhabditis amazonensis MC01 & $5.0 \pm 1.2 \mathrm{a}$ \\
Beauveria bassiana & $0.0 \pm 0.0 \mathrm{~b}$ \\
Control & $0.0 \pm 0.0 \mathrm{~b}$ \\
CV $(\%)$ & 37.49 \\
\hline
\end{tabular}

*Means \pm standard deviation followed by the same letter in the column do not differ significantly by the Tukey test at $5 \%$ significance.

\section{DISCUSSION}

The nematode $H$. amazonensis MC01 was used since it is a population found in the region where the experiments were carried out, thus being better adapted to local conditions. In addition, according to Guide et al. (2018), high larval mortality rates were obtained with $H$. amazonensis isolates RSC5 and GL, 100\% and 97\%, respectively, and $H$. amazonensis GL was one of the nematodes that caused the highest adult mortality, $54 \%$. 
The greater potential of both entomopathogens to kill larvae than adults, observed in both experiments, may be associated with the difficulty in penetrating in the rigid integument of the adult insect. Benavides-Machado, Quintero and López (2010) argue that variations in the susceptibility of H. hampei larvae and adults to entomopathogenic nematodes, for example, may be associated with morphological and behavioral differences at each stage of insect development. The larvae has a less chitinized cuticle, with more exposed spiracles and lower mobility, facilitating IJ penetration, while adults, in addition to presenting a more rigid integument, have spiracles protected by elytra, besides well-developed jaws.

Cuthbertson and Audsley (2016) evaluated fungi and entomopathogenic nematodes for the control of Drosophila suzukii (Matsumura) (Diptera: Drosophilidae), an insect in which the larvae, as well as those of $H$. hampei, remain inside the fruit, in an environment of difficult access, which makes control difficult. The authors observed that the nematode Heterorhabditis bacteriophora and the fungus Isaria fumosorosea acted mainly in the larval stage of the insect, causing up to $95 \%$ mortality. However, they found that the nematodes did not work well when applied to the pending fruits on the plant, but when sprayed directed to the soil, via drench.

Lara, Lopez and Bustillo (2004) applied Heterorhabditis sp. and Steinernema sp. directed to the soil in order to reach the borer present in the fallen fruits, and verified that the nematodes caused mortality of up to $82 \%$ and $88 \%$ of insects, respectively, concluding that infective juveniles were able to penetrate the fruit and that they caused mortality mainly in larvae.

Acevedo and Núñez (2009) found that $H$. bacteriophora is capable of causing an average mortality of $46 \% \mathrm{H}$. hampei, confirming the ability of IJ to penetrate coffee fruits and cause insect mortality of larvae, pupae and adults. However, this result differs from that found by Guide et al. (2018) who, despite having observed 100\% mortality of H. hampei larvae when Heterorhabditis spp. and S. feltiae were applied directly to the insects, found that when they were applied to bored fruits, infective juveniles were not able to penetrate the fruit.

Sánchez and Rodríguez (2007) applied $H$. bacteriophora directly to the insect in a laboratory test and obtained mortality results of $100 \%$ for larvae and pupae. When the bored fruits were placed in trays containing soil, simulating a field situation, $60 \%$ mortality rates were obtained, reaching $93 \%$ after 17 days.

In this study, as observed by Acevedo and Núñez (2009), it was found that infective juveniles were able to kill larvae and adults within the fruit since, in one of the experiments, nematode and fungus were applied to vermiculite, having to penetrate the fruits to find the host.
Results presented by Manton, Hollingsworth and Cabos (2012) demonstrate that $S$. carpocapsae was able to cause mortality at the different development stages of coffee borer when applied to the soil directed at fallen fruits, causing mortality of $26.6 \%$ in adults and $23.7 \%$ in larvae. Guide et al. (2018) obtained similar values when testing $S$. carpocapsae for adults, $22 \%$. However, the values found for larvae were higher, $87.5 \%$. Benavides-Machado, Quintero and López (2010) obtained adult mortality rates of up to $24.6 \%$ when using $H$. bacteriophora. These values were similar to that found in this study for adults, when $H$. amazonensis was applied to vermiculite, $27.97 \%$ (Table 1).

Vera et al. (2011) found that B. bassiana was able to decrease $H$. hampei infestation by up to $50 \%$, with mortality of $40 \%$ of insects, including larvae, pupae and adults, similar to the value found in this study for H. hampei adults. In addition, the authors observed a decrease in the population of $H$. hampei when the fungus is applied to bored fruits that fall on the soil, reducing future generations of the pest. These results reinforce the data presented in this study, where values of up to $86 \%$ larval mortality and $44 \%$ adult mortality were obtained, demonstrating the potential use of B. bassiana, mainly in the control of coffee borer.

Studies associating entomopathogens have been developed in order to verify the synergistic effect on the control of Curculionidae considered agricultural pests. Ansari, Shah and Butt (2008) obtained mortality rates of up to $100 \%$ when associating Metarhizium robertsii with $S$. kraussei or H. bacteriophora in the control of Otiorhynchus sulcatus (Fabricius) (Coleoptera: Curculionidae). The association of $B$. bassiana and $S$. carpocapsae was considered beneficial in the control of Hylobius abietis L. (Coleoptera: Curculionidae), with a smaller number of adults emerging when using the entomopathogens together (Williams et al., 2013).

Simi et al. (2018) studied the combined action of Steinernema brazilense and B. bassiana in the control of Conotrachelus humeropictusos (Fiedler) (Coleoptera: Dryophthoridae), and found that there was a synergistic interaction in the joint application of the two entomopathogens, causing mortality of up to $65.6 \%$ insects, which corresponded to a $15.6 \%$ increase in mortality when compared to the application of the nematode alone. In addition, the authors also observed that infective juveniles were able to transport $B$. bassiana conidia through the soil at a depth between 0.07 and $0.10 \mathrm{~m}$. Conidial transport was observed in this study when it was found that B. bassiana was capable of causing $70 \%$ mortality of T. molitor larvae when applied together with $H$. amazonensis on the side opposite to the presence of the larvae (Table 6), as well as when fungal conidia were visualized together with infective juveniles on the opposite side of their release in Petri dishes with agar (Table 7). 
The increase in insect mortality when associated with different entomopathogens can be associated with stress caused by one of the control agents, which can weaken the insect and increase susceptibility to the other pathogen, increasing insect mortality or even reducing lethal time (Shaohui et al., 2014).

However, antagonistic effects have also been observed. Shapiro-Ilan et al. (2004) found synergism in the association of entomopathogens in the control of Curculio caryae (Horn) (Coleoptera: Curculionidae) larvae only when $H$. indica and $M$. anisopliae were tested together. The other associations tested involving B. bassiana, M. anisopliae, Isaria fumosorosea and the bacterium Serratia marcescens were considered antagonistic. In this study, an antagonistic effect was observed only when the joint application was made to vermiculite to control adults (Table 1), obtaining less than $1 \%$ of insect mortality. According to Tarasco et al. (2011), antagonistic effects may be related to compounds released both by fungi and by the symbiotic bacteria of entomopathogenic nematodes.

Although no additive effect was observed between the fungus and the nematode under the tested conditions, it is possible to observe the action potential of these organisms, even if in isolation, on coffee borer due to the mortality rates found at two stages of insect development. In addition, it must be considered that, in the laboratory, it is easier for the pathogen to find and contact the host, which may have reflected in the nonobservation of an additive effect in the associated application.

Even though synergism was not observed when $H$. amazonensis MC01 and B. bassiana UFU01 were applied together in order to cause mortality in H. hampei larvae and adults, tests under field conditions should be carried out to verify if the nematode ability to search for the host in the field and to transport fungal conidia can increase insect mortality rates, by providing greater reach to the fungus to the insects located inside the fruit when fallen in the soil, thus being one more possible strategy to increase pest mortality factors.

\section{CONCLUSIONS}

Beauveria bassiana UFU01 and $H$. amazonensis MC01 were considered pathogenic to $H$. hampei, causing larval and adult mortality when applied alone and also associated. When applied to vermiculite, the association between nematode and B. bassiana UFU01 was not able to cause adult mortality.

Heterorhabditis amazonensis $\mathrm{MC} 01$ is capable of transporting B. bassiana UFU01 conidia, which was observed due to the mortality of $T$. molitor larvae. When associated with fungus and the nematode, B. bassiana caused higher mortality of T. molitor larvae than infective juveniles.

Infective juveniles transported $B$. bassiana UFU01 conidia adhered to their cuticle to the opposite side of the Petri dish, thus highlighting the occurrence of phoresis between $H$. amazonensis MC01 and B. bassiana UFU01.

\section{REFERENCES}

ACEVEDO, J. P. M.; NÚÑES, J. C. L. Efeito da aplicação de nematoides entomopatogênicos sobre frutos infestados com broca-do-café, Hypothenemus hampei (Coleoptera: Scolytidae). Nematologia Brasileira, 33:115-122, 2009.

ALLARD, G. B.; MOORE, D. Heterorhabditis sp. nematodes as control agents for the coffee berry borer, Hypothenemus hampei (Scolytidae). Journal of Invertebrate Pathololgy, 54(1):45-48, 1989.

ANSARI, M. A.; SHAH, F. A.; BUTT, T. M. Combined use of entomopathogenic nematodes and Metarhizium anisopliae as a new approach for black vine weevil, Otiorhynchus sulcatus, control. Entomologia Experimentalis et Applicata, 129(3):340-347, 2008.

BENAVIDES-MACHADO, P.; QUINTERO, J. C.; LÓPEZ, J. C. Evaluación en el laboratorio de nematodos entomopatógenos nativos para el control de la broca del café. Cenicafé, 61(2):119-131, 2010.

BRASIL. Ministério da Agricultura, Pecuária e Abastecimento. Agrofit. 2020. Available in: $<$ http:// agrofit.agricultura.gov.br/agrofit_cons/principal_agrofit cons $>$. Access in: June, 17, 2020.

CARVAlHO, J. P. F.; SOUZA, J. C. de. Manual de prevenção e combate à broca-do-café. 2020. Available in: <http:/www.sapc.embrapa.br/arquivos/consorcio/ publicacoes_tecnicas/manual-combate-a-broca.pdf $>$. Access in: June, 17, 2020.

COMPANHIA NACIONAL DE ABASTECIMENTO CONAB. Acompanhamento da safra brasileira de café. Brasília, v. 6, safra 2020, n. 1 - Primeiro levantamento, 2020. 62p.

CUTHBERTSON, A. G. S.; AUDSLEY, N. Further screening of entomopathogenic fungi and nematodes as control agents for Drosophila suzukii. Insects, 7(2):1-9, 2016.

DAMON, A. A review of the biology and control of the coffee berry borer, Hypothenemus hampei (Coleoptera: Scolytidae). Bulletin of Entomological Research, 90:453-465, 2000.

DIVYA, K.; SANKAR, M. Entomopathogenic nematodes in pest management. Indian Journal of Science and Technology, 2(7):53-60, 2009.

DOLINSKI, C. et al. Studies on entomopathogenic nematodes in Brazil: Past and future. Nematoda, 4:e102017, 2017. 
GUIDE, B. A. et al. Selection of entomopathogenic nematodes and evaluation of their compatibility with cyantraniliprole for the control of Hypothenemus hampei. Semina: Ciências Agrárias, 39(4):1489-1502, 2018.

INFANTE, F.; PÉREZ, J.; VEGA, F. E. Redirect research to control coffee pest. Nature, 489: 502, 2012.

LARA, J. C. G.; LOPEZ, J. C. N.; BUSTILLO, A. E. P. Effect of entomopathogenic nematodes on populations of the coffee berry borer, Hypothenemus hampei (Coleoptera: Scolytidae), in berries on the soil. Revista Colombiana de Entomología, 30(2):179-185, 2004.

MANTON, J. L.; HOLLINGSWORTH, R. G.; CABOS, R. Y. M. Potential of Steinernema carpocapsae (Rhabditida: Steinernematidae) against Hypothenemus hampei (Coleoptera: Curculionidae) in Hawai'i. Florida Entomologist, 95(4):1194-1197, 2012.

MONZÓN, A. J.; GUHARAY, F.; KLINGEN, I. Natural occurrence of Beauveria bassiana in Hypothenemus hampei (Coleoptera: Curculionidae) populations in unsprayed coffee fields. Journal of Invertebrate Pathology, 97(2):134-141, 2008.

OLIVEIRA, C. M. et al. Economic impact of exotic insect pests in Brazilian agriculture. Journal of Applied Entomology, 137(1-):1-15, 2013.

PARRA, J. R. P.; REIS, P. R. Manejo integrado para as principais pragas da cafeicultura, no Brasil. Visão Agrícola, 8(12):47-50, 2013.

PLATA-RUEDA, A. et al. Exposure to cyantraniliprole causes mortality and disturbs behavioral and respiratory responses in the coffee berry borer (Hypothenemus hampei). Pest Management Science, 75(8):2236-2241, 2019.

POTRICH, T. D. et al. Metodologia de criação de Tenebrio molitor em laboratório para obtenção de larvas. Passo Fundo (RS): Embrapa Trigo. Documentos Online 82, 2007. 1p.
SÁNCHEZ, L.; RODRÍGUEZ, M. G. Potencialidades de Heterorhabditis bacteriophora Poinar cepa HC1 para el manejo de Hypothenemus hampei Ferr. I. Parasitismo y capacidad de búsqueda. Revista de Protección Vegetal, 22(2):80-84, 2007.

SHAOHUI, W. et al. Interaction between entomopathogenic nematodes and entomopathogenic fungi applied to third instar southern masked chafer white grubs, Cyclocephala lurida (Coleoptera: Scarabaeidae), under laboratory and greenhouse conditions. Biological Control, 76:65-73, 2014.

SHAPIRO-ILAN, D. I. et al. Effects of combining an entomopathogenic fungi or bacterium with entomopathogenic nematodes on mortality of Curculio caryae (Coleoptera: Curculionidae). Biological Control, 30(1):119-126, 2004.

SIMI, L. D. et al. Mortality of Conotrachelus humeropictus in response to combined application of the nematode Steinernema Brazilense and the fungus Beauveria bassiana. Arquivos do Instituto Biológico, 85:e0092016, 2018.

SOUZA, J. C. et al. Controle químico da broca-do-café com cyantraniliprole. Coffee Science, 8(4):404-410, 2013.

TARASCO, E. et al. Laboratory studies on the competition for insect haemocoel between Beauveria bassiana and Steinernema ichnusae recovered in the same ecological niche. Biocontrol Science and Technology, 21(6):693-704, 2011.

VERA, J. T. et al. Evaluation of Beauveria bassiana (Ascomycota: Hypocreales) as a control of the coffee berry borer Hypothenemus hampei (Coleoptera: Curculionidae: Scolytinae) emerging from fallen, infested coffee berries on the ground. Biocontrol Science and Technology, 21(1):1-14, 2011.

WILLIAMS, C. D. et al. Control of a major pest of forestry, Hylobius abietis, with entomopathogenic nematodes and fungi using eradicant and prophylactic strategies. Forest Ecology and Management, 305:212-222, 2013. 